\title{
GRAVIMETRIC GEOID MODELLING OVER PENINSULAR MALAYSIA USING TWO DIFFERENT GRIDDING APPROACHES FOR COMBINING FREE AIR ANOMALY
}

\author{
M F Pa'suya ${ }^{1,2^{*}}$,A H M Din ${ }^{2,3}$, J. C. McCubbine ${ }^{4}$,A.H.Omar ${ }^{2}$, Z. M. Amin ${ }^{3}$ and N.A.Z.Yahaya ${ }^{2}$ \\ ${ }^{1}$ Center of Studies for Surveying Science and Geomatics, Faculty of Architecture, Planning \& Surveying, Universiti Teknologi \\ MARA, Perlis, Arau Campus, 02600 Arau, Perlis - faiz524@uitm.edu.my \\ ${ }^{2}$ Geomatics Innovation Research Group (GNG),${ }^{3}$ Geoscience and Digital Earth Centre (INSTEG), Faculty of Built Environment and \\ Surveying, Universiti Teknologi Malaysia, 81310 Johor Bahru, Johor, Malaysia- amihassan@utm.my \\ ${ }^{4}$ Geodesy Section, Community Safety and Earth Monitoring Division, Geoscience Australia, GPO Box 378, Canberra, ACT 2601, \\ Australia- jack.c.mccubbine@googlemail.com
}

KEY WORDS: LSMSA, KTH method ,gravimetric geoid, Peninsular Malaysia

\begin{abstract}
:
We investigate the use of the KTH Method to compute gravimetric geoid models of Malaysian Peninsular and the effect of two differing strategies to combine and interpolate terrestrial, marine DTU17 free air gravity anomaly data at regular grid nodes. Gravimetric geoid models were produced for both free air anomaly grids using the GOCE-only geopotential model GGM GO_CONS_GCF_2_SPW_R4 as the long wavelength reference signal and high-resolution TanDEM-X global digital terrain model. The geoid models were analyzed to assess how the different gridding strategies impact the gravimetric geoid over Malaysian Peninsular by comparing themto 172 GNSS-levelling derived geoid undulations. The RMSE of the two sets of gravimetric geoid model / GNSS-levelling residuals differed by approx. $26.2 \mathrm{~mm}$.. When a 4-parameter fit is used, the difference between the RMSE of the residuals reduced to $8 \mathrm{~mm}$. The geoid models shown here do not include the latest airborne gravity data used in the computation of the official gravimetric geoid for the Malaysian Peninsular, for this reason they are not as precise.
\end{abstract}

\section{INTRODUCTION}

\subsection{General Instructions}

The geoid can be defined as an equipotential surface of the Earth's gravity field which almost coincides with the mean sea level (MSL). Various method exist to compute regional geoid models e.g. the Remove-Compute-Restore (RCR) approach (Forsberg 1991), Helmert's scheme (Vaníček et al., 1995), Bruns's ellipsoidal formula (Ardalan and Grafarend 2004), and least square modification of Stokes formula (Sjöberg, 2003a, and 2005). Each method employs different techniques and philosophy, and although the theoretical differences are well understood it is important to explore the differing results of their practical application to obtain an optimal result.

In 2003 an airborne gravity survey was performed by the Geodynamics Dept. of the Danish National Survey and Cadastre in cooperation with Department of Survey and Mapping Malaysia (DSMM) under Malaysia geoid project (MyGEOID). The intention of the data collection was to produce a new regional geoid model over the Malaysian Peninsular with unprecedented accuracy. The geoid model was determined using the RCR technique with 5634 existing terrestrial gravity data points, 24855 points of airborne gravity and new GRACE satellite data (GGM01C).

Least square modification of Stokes formula has become a popular alternative to the RCR technique to compute gravimetric geoid models. This method was developed at the Royal Institute of Technology (KTH) and has been successfully applied in many regions such as Uganda (Sjöberg et al., 2015), Iran (Kiamehr, 2006), Sudan (Abdalla and Fairhead, 2011), New Zealand (Abdalla, \& Tenzer, 2011), Sweden (Ågren et al., 2009), Peninsular Malaysia (Sulaiman et al., 2014) and northern region of Peninsular Malaysia (Pa'suya et al., 2018). Here we explore the use of the KTH over the whole Malaysian Peninsular.

Further, due to the large amount of coastline regional geoid models of the Malaysian Peninsular are heavily influenced by off-shore gravity anomalies. These are usually derived from satellite altimetry data. The optimal combination of these data with terrestrial gravity observations (which have different levels of accuracy) is a crucial consideration prior to modelling the quasigeoid. We analyse the effect of two different strategies, (i) following McCubbine et al. (2018) and (ii) Kiamehr (2007), on the regional geoid models determined via the KTH method with respect to GNSS-levelling derived geoid undulations. Only terrestrial and marine gravity data have been used in the computations we present.

\section{REGIONAL GRAVITY DATA}

\subsection{Land gravity data}

Terrestrial gravity observations over Malaysia have been performed by the Department of Survey and Mapping Malaysia (DSMM) since 1988. In addition, the University of Teknologi Malaysia (UTM) and Geological Survey Department Malaysia (GSDM) have also contributed terrestrial gravity data to DSMM. The DSMM database currently (2019) consists of 8474 observations covering Peninsular Malaysia (Fig.1). The terrestrial gravity database contains many duplicate points and the horizontal positions and heights of the points are determined from by varying methods. For the horizontal position, each gravity point was defined from the three methods, (i) estimated from topographic maps, (ii) measured using handheld GPS and (iii) via the most modern modern technique, RTK GPS. Before 
the GNSS era, most of the horizontal positions of each gravity station was estimated from the topographic maps available at the time of observation. Any erroneous positions can introduce error or bias in the computation of gravity anomaly e.g. $100 \mathrm{~m}$ position variation $0.1 \mathrm{mGal}$ in normal gravity (Amos,2007).

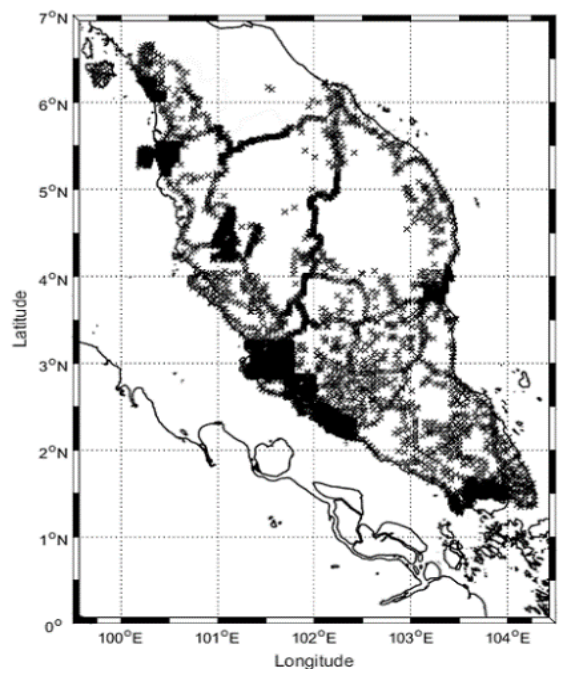

Figure 1. Distribution of land gravity stations over Peninsular Malaysia

The recorded heights of the gravity station were either measured using barometers, read from the topographical map or measured by differential leveling. Inconsistency in these surveying techniques to determine the horizontal and vertical position will affect the precision of the data. With these considerations we have scrutinized the database to ensure all the terrestrial data is free of gross and systematic errors as a pre-processing stage (Kiamehr, 2007).

We performed two steps in the cleaning process. First a visual inspection using MS-Excel software to detect any duplicate points based on the same latitude, longitude and gravity value. A total of 222 points were eliminated after visual inspection. Second using of the cross validation approach and details about this method have been discussed by Kiamehr (2007). Overall, after first and second steps of cleaning process, a total of 461 points were detected as outliers and eliminated from the database, representing $5.4 \%$ from the original amount (8474 points).

\subsection{Satellite altimetry-derived gravity anomalies}

Satellite altimetry data can be used to determine gravity anomalies in the marine region. There are numerous data sets of this type e.g KMS02 (Andersen and Knudsen, 1998), DTU model (Andersen \& Knudsen, 2019), Sand well and Smith model (Sandwell et al., 2014), GSFC00 (Hwang et al., 2002) among others. Each model has been computed via different mathematical modelling procedures and reference models (e.g. EGM96, EGM2008). Currently, Danish Technical University (DTU) has released four versions of DTU model, which are DTU10, DTU13, DTU15 and the latest model is DTU17. DTU10 can be downloaded free via DTU website but other models need to be specially requested from the DTU team.

In this study, all the satellite-altimeter-derived marine gravity anomalies have been validated using 15614 marine ship-borne gravity observations provided by Bureau Gravimétrique
International (BGI), (http://bgi.obs-mip.fr). The shipborne data were filtered first to remove gross errors. The statistical analysis of validation is reported in Table 1. The DTU17 model has the best agreement with the shipborne data having residuals with minimum, maximum, mean and standard deviation of 0.00102 , $86.599,7.329$ and $10.762 \mathrm{mGal}$, respectively. Satellite altimetry derived gravity anomalies are notoriously problematic in shallow coastal areas. For this reason, data from the DTU17 model have been removed 20 kilometres from the coastal boundary (see Fig. 2).

Table 1. The statistics of the differences between the satellite altimetric gravity model and 15614 shipborne gravity data; unit [mGal].

\begin{tabular}{ccccc}
\hline Model & Min & Max & Mean & STD \\
\hline DTU13 & 0.0035 & 87.012 & 7.387 & 10.818 \\
DTU15 & 0.00034 & 86.761 & 7.339 & 10.767 \\
DTU17 & $\mathbf{0 . 0 0 1 0 2}$ & $\mathbf{8 6 . 5 9 9}$ & $\mathbf{7 . 3 2 9}$ & $\mathbf{1 0 . 7 6 2}$ \\
Sandwell & 0.00011 & 92.220 & 8.719 & 12.113 \\
\hline
\end{tabular}

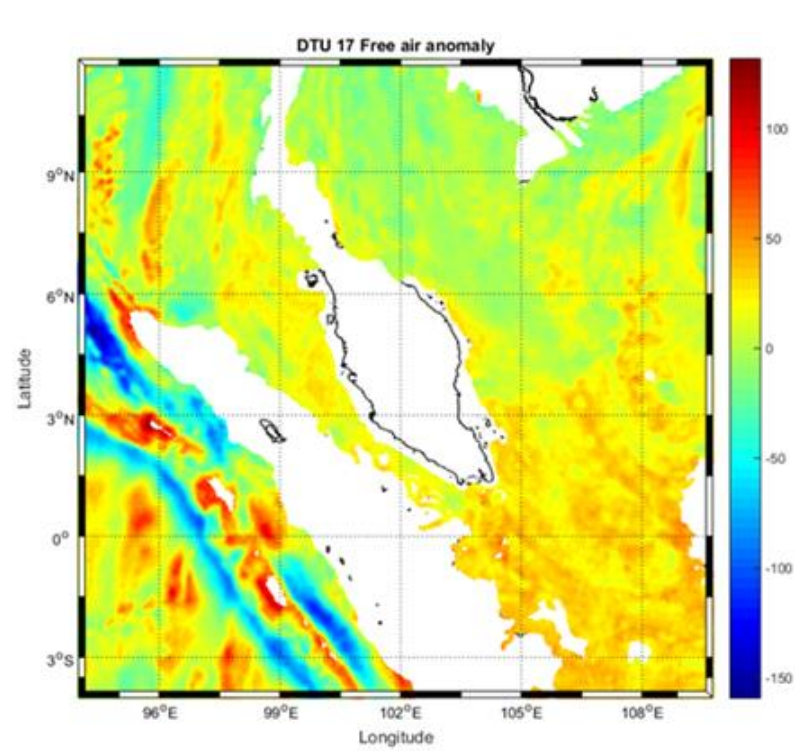

Figure 2 Free air anomaly from DTU 17 model

\subsection{Global Digital Elevation Model (GDEM)}

In this study, the newly released DEM model, TanDEM-X DEM by German Aerospace Center (DLR) has been used in the KTH method geoid modeling process. This new global DEM can be considered as the most consistent, accurate and most complete global DEM data set of the Earth's surface (Wessel et al., 2018) today. The accuracy of the TanDEM-X DEM has been analysed by many scientists around the world using various methods. Unfortunately, the accuracy of DEMs over Peninsular Malaysia have never been studied. Since the vertical position of the terrestrial gravity data are not consistent with each other, heights from the TanDEM-X DEM was extracted and used to derive the free air anomaly from the terrestrial gravity data. This was performed so that the data reductions are in terms of a consistent vertical datum. Also, the TanDEM-X DEM has been used in the computation of Bouger gravity correction, combined topographic correction and the downward continuation effect. 


\subsection{Global Geopotential Model (GGM)}

In the computation of a gravimetric geoid model over Peninsular Malaysia, the most accurate satellite-only GGMs and combined GGMs were selected by evaluating their accuracy with 173 GNSS/Levelling data (Fig. 10). Amongst the combined GGMs, EIGEN-6C4 model fitted the GNSS/Levelling derived geoid height the best. This model was used in preparing of the surface gravity anomaly using one of the strategies which proposed in the next section. Meanwhile, satellite-only GGMs, GO_CONS_GCF_2_SPW_R4 up to degree 130 was selected in the geoid processing using KTH method, since this GGM is the most accurate satellite-only model over Peninsular Malaysia and independent of all of the datasets, avoiding the errors that may arise in combined GGMs (Ågren et al., 2009). The modification of degree value (130) was optimized by parameters sweeps over a range of 10 to 240 degree.

\section{METHODOLOGY}

\subsection{Strategy of combining data and gridding process}

As mentioned previously, two strategies have been used to combine and grid the free air anomalies using the land gravity and marine data. For the marine region, only free air anomalies derived from satellite altimetry DTU17 have been used and the ship-track gravity data in the database excluded. This is because the gravity anomaly from the ship observation is usually affected by several errors such as instrumental errors, navigational errors, inconsistent use of reference systems etc. (Denker and Roland 2005). Figure 4 shows the distribution of land gravity anomalies and DTU17 over the Malaysia Peninsular and the flow chart of the two different strategies is shown in Fig. 5.

The first strategy is commonly used with the KTH method. This is (discussed in detail by Kiamehr, 2007) as follows:

i. Compute the simple Bougeur correction to reduce the surface free air gravity anomalies, $\Delta \mathrm{g}$ (land and marine) to simple Bougeur gravity anomalies, $\Delta$ gr.

$$
\begin{aligned}
& \Delta t c=0.1119 H \\
& \Delta g r=\Delta g-\Delta t c
\end{aligned}
$$

where $H$ is the orthometric height derived from the

\section{TanDEM-X DEM}

ii. Interpolate the simple Bougeur gravity anomalies, $\Delta \mathrm{g}$ ' to a regular grid (e.g. 1 minute $\mathrm{x} 1$ minute resolution), Here we have ussed least square collocation (LSC). This is a commonly used method for interpolation of gravity functionals.

iii. Since the KTH method works on the full gravity anomaly without reduction (Sjöberg, 2003), the topographic correction are restored to the grid point to obtain gridded surface free air gravity anomalies.

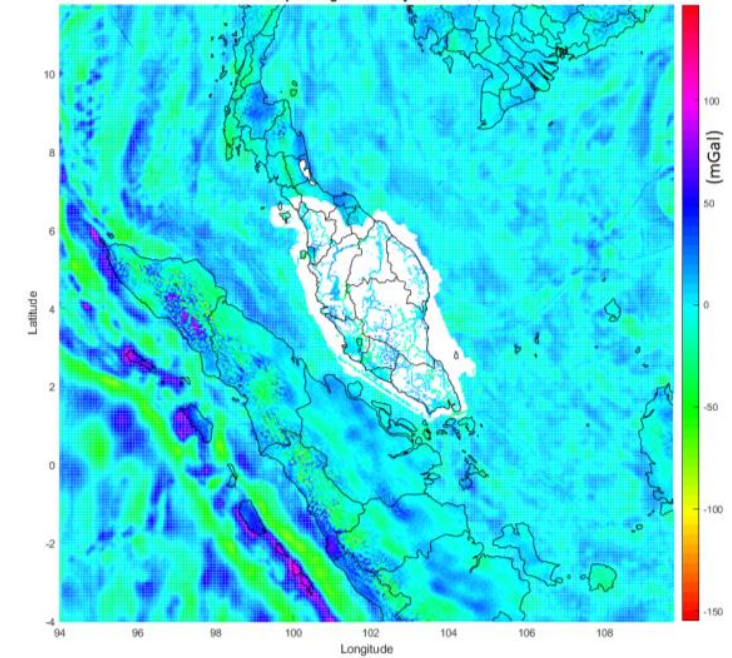

Figure 4 Distribution of land gravity anomalies and DTU17 over Peninsular Malaysia.

The second method to combine the land and marine gravity anomalies was used in McCubbine et al. (2017). In general, the second strategy is slightly different from the first strategy in which this strategy removed the topographic correction and long-wavelength part from the surface gravity anomalies to obtain residual gravity anomalies. The long-wavelength part was computed from a global geopotential model (GGM), EIGEN-6C4, and long wavelength topographic effect computed from Earth2012 (which has the same spectral content as Eigen6C4). Eigen-6C4 is the most accurate combined model over Peninsular Malaysia after evaluation using 173 GNSS/leveling data. Details of the second strategy are as follows:

i. Compute the simple Bouguer correction, $\Delta$ tc using Eq.(1)

ii. Compute the long-wavelength part, $\Delta \mathrm{gl}$ from the selected GGM using GrafLab (Irregular Surface GRAvity Field LABoratory) software (Bucha and Janák, 2014)

iii. Perform spherical harmonic synthesis of the Earth2012 model to determine the long wavelength topography, which is then used to calculate the long wavelength topographic effect $\Delta \mathrm{tc} \_$.

iv. Subtract the topographic correction, $\Delta \mathrm{tc}$ and longwavelength gravity part , $\Delta \mathrm{gl}$ and long wavelength topographic effect $\Delta \mathrm{tc} \_$l to obtain residual gravity anomalies, $\Delta \mathrm{gr}$

$$
\Delta g r=\Delta g-\Delta t c-(\Delta g l-\Delta t c l)
$$

v. Interpolated the residual gravity anomalies, $\Delta \mathrm{g}^{\text {' to a }}$ regular grid using least square collocation (LSC)

vi. Finally, the topographic corrections and longwavelength gravity parts are restored to the gridded residual values to produce gridded surface gravity anomalies 


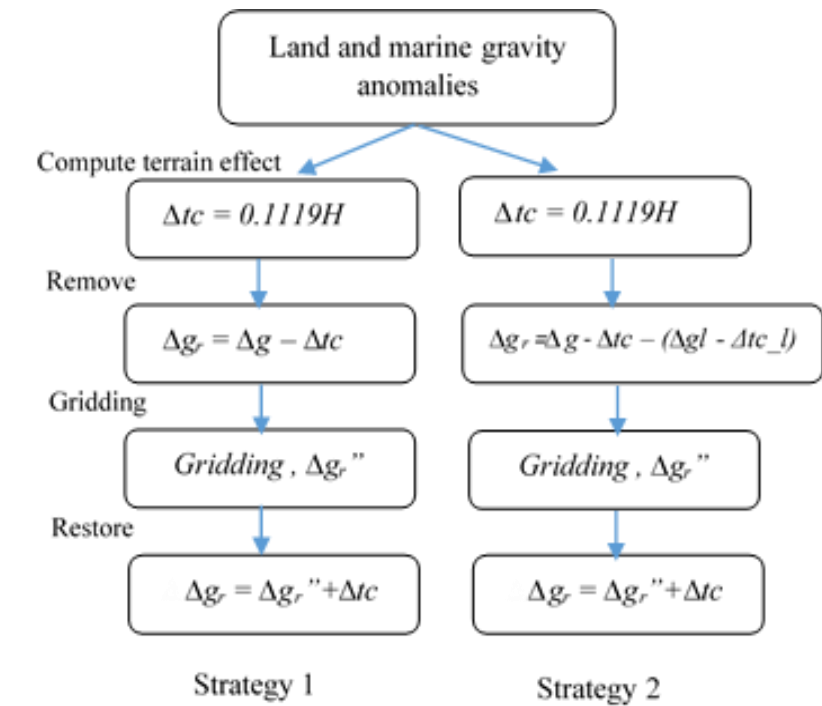

Figure 5 Two strategies for gridding of the free air anomaly

Figure 6 shows the difference between 1'x1'grid of surface free air gravity anomalies computed via first strategy and second strategy, respectively. Meanwhile, the statistical analysis of the both gridded surface anomalies is reported in Table 2. As shown in Table 2, the mean and standard deviation of the gridded surface gravity anomaly from the Strategy 2 give lower value than Strategy 1.

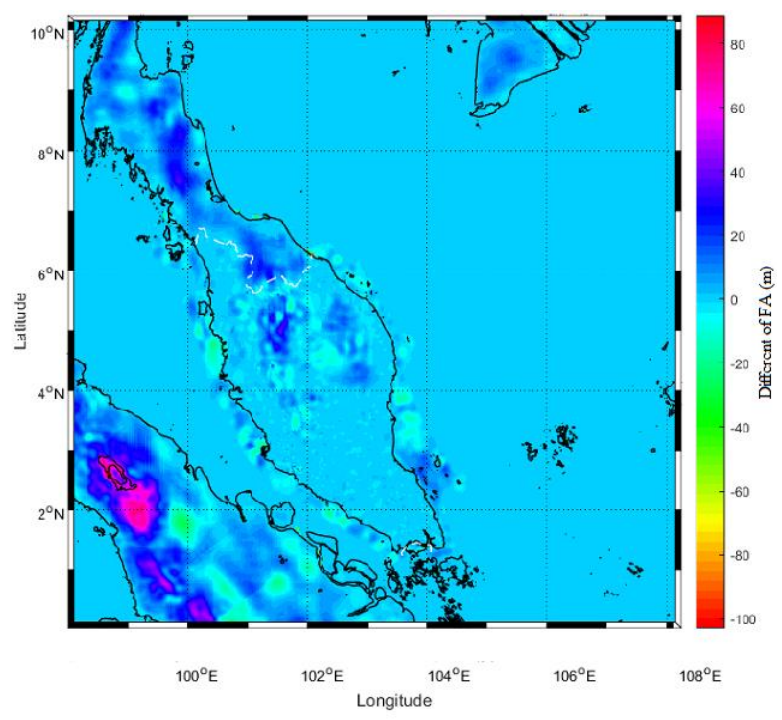

Figure 6 Different of gridded surface gravity anomaly between Strategy 1 and Strategy 2 (Unit: mGal)

Table 2 Statistical analysis about the free air anomaly from two strategies (Unit: $\mathrm{mGal}$ )

\begin{tabular}{ccccc}
\hline Strategy & Min & Max & Mean & Std \\
\hline 1 & -119.715 & 426.197 & 18.544 & 34.763 \\
\hline 2 & -158.983 & 423.868 & 14.589 & 33.244 \\
\hline
\end{tabular}

\subsection{Gravimetric geoid modeling using KTH method}

Computation of the gravimetric geoid using LSMS or KTH method has been discussed in detail by Sjöberg et al. (2015), Ågren (2004) and Ågren et al. (2009). In general, the Least
Squares Estimator for the geoid height of the KTH method is given by Sjöberg (2003b) as follows:

$$
\begin{aligned}
& N^{L, M}=\frac{R}{4 \pi \gamma} \iint_{\sigma_{0}} S^{L}(\psi) \Delta g d \sigma+c \sum_{n=0}^{M}\left(Q_{n}^{L}+s_{n}\right) \Delta g_{n}^{G G M}+ \\
& \delta N_{c o m b}^{T}+\delta N_{d w c}+\delta N_{\text {tot }}^{a}+\delta N_{\text {tot }}^{e}
\end{aligned}
$$

where $\sigma_{0}$ is the spherical cap, $\mathrm{R}$ is the mean Earth radius, $\mathrm{g}$ is mean normal gravity, $S^{L}(\psi)$ is the modified Stokes' function, $s_{n}$ are the modification parameters, $\mathrm{M}$ is the maximum degree of the Global Geopotential Model (GGM), $\mathrm{n}$ are the Molodensky truncation coefficients and $\Delta \mathrm{g}_{\mathrm{n}}{ }^{\mathrm{GGM}}$ is the Laplace surface harmonic of the gravity anomaly determined by the GGM of degree n. Briefly in the KTH method, the Stokes' formula (truncated to a cap) is applied to the unreduced surface gravity anomaly to obtain approximate geoid model and then the additive correction were added to obtain final gravimetric geoid, $\mathrm{N}$.

\subsubsection{Optimum Least Squares Modification Parameters}

Determination of the least squares modification parameters was computed using the correlated model. In order to obtain optimum least square modification parameter, several condition parameters such as standard deviations for the terrestrial gravity data $\left(\sigma_{\Delta \mathrm{g}}\right)$, correlation length $(\Psi)$, limited cap size $\left(\Psi_{0}\right)$, upper limits of the GGM (M) and Stokes' function (L) should be numerically studied. Here, satellite only global gravity model GO_CONS_GCF_2_SPW_R4 was used in KTH processing, since it is independent of all of the datasets and the most accurate satellite only over Peninsular Malaysia. According to Sulaiman et al. (2014), the best value of combination parameter is $\mathrm{M}=\mathrm{L}=180, \Psi_{0}=3.0^{\circ}, \Psi_{0}=0.4^{\circ}$ and $\sigma_{\Delta \mathrm{g}}=5.0 \mathrm{mGal}$. However, the $\mathrm{M}=\mathrm{L}$ and $\Psi_{0}=3.0^{\circ}$ is set as 130 and $2.5^{\circ}$, respectively, after testing them over a range of $10-240$ degree and $1^{\circ}-3^{\circ}$, respectively.

\subsubsection{Determination of Approximate Geoid Height}

The approximate geoid height model for Peninsular Malaysia computed from GGM GO_CONS_GCF_2_SPW_R4 and a 1 'x1'grid of the surface gravity anomalies obtained from the two strategies is shown in Figure 7a (Strategy 1) and 7b (Strategy 2).

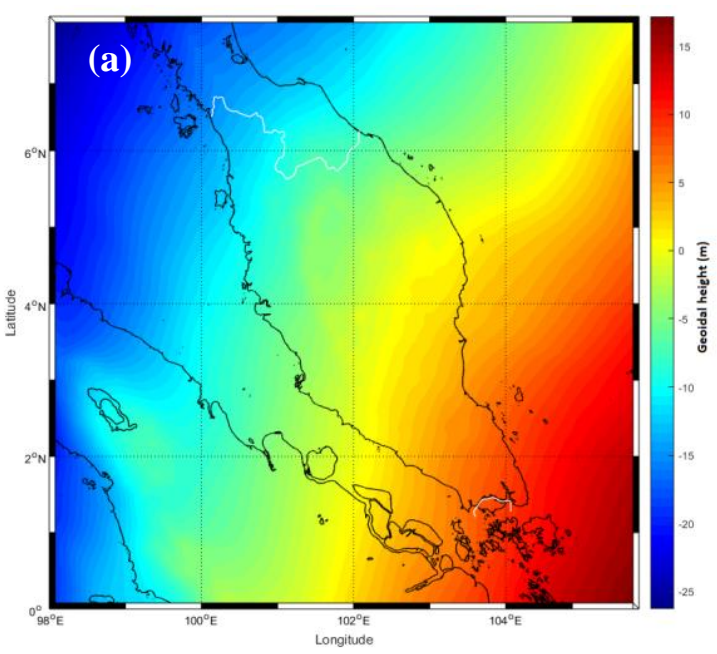




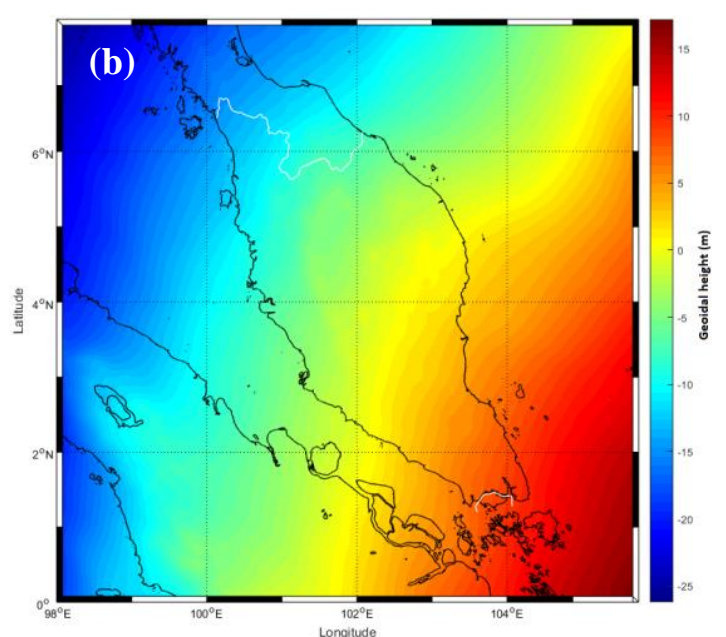

Figure 7. Approximate geoid height from strategy 1(a) and strategy 2 (b)

Interestingly, the approximate geoid model is decreasing towards the northwest from positive to negative value as shown in Figure 7, which means that the geoid at the northern region is below the GRS80 ellipsoid.

\subsubsection{Additive Corrections}

As discussed in section 3.2, four additive corrections including the combined topographic correction, downward continuation correction, combined atmospheric correction and ellipsoidal correction were computed separately one by one and added to the approximate geoid height to produce final gravimetric geoid. The results for the four additive correction are presented in Figure 8. The four additive corrections were computed using the following equation and details about the equation can be found in Ågren et al. (2009):

\section{Topographic correction (Sjöberg, 2007)}

The topographic correction was computed using Eq.5 using the height extracted from the TanDEM-X DEM.

$\delta N_{\text {comb }}^{\text {Top }}=\delta N_{\text {dir }}+\delta N_{\text {ind }}^{\mathrm{Top}}=-\frac{2 \pi G \rho H^{2}}{\gamma}\left(1+\frac{2 H}{3 R}\right)$

where $G$ is the Newtonian gravitational constant, $\rho$ is the Earth's crust density, $\mathrm{R}$ is the earth radius and $\mathrm{H}$ is the elevation of the topography at the computation point, $\mathrm{P}$.

\section{Downward continuation (DWC) correction (Sjöberg 2003b)}

The Downward Continuation (DWC) correction is determined using the TanDEM-X DEM and the chosen GGM GO_CONS_GCF_2_SPW_R4 with $\mathrm{M}=130$. The DWC correction was computed using Eq.6

$$
\delta N_{\mathrm{DWC}}=\delta N_{\mathrm{dwc}}^{(1)}+\delta N_{\mathrm{dwc}}^{L 1, \mathrm{Far}}+\delta N_{\mathrm{dwc}}^{L 2}
$$

where

$$
\begin{aligned}
& \delta N_{\mathrm{dwc}}^{(1)}=\frac{\Delta g P}{\gamma} H_{P}+3 \frac{\tilde{N}}{r_{p}} H_{P}-\left.\frac{1}{2 \gamma} \frac{\partial \Delta g}{\partial r}\right|_{P} H_{P}^{2} \\
& \delta N_{\mathrm{dwc}}^{L 1, \mathrm{Far}}=\frac{R}{2 \gamma} \sum_{n=2}^{M} b_{n}\left[\left(\frac{R}{r_{P}}\right)^{n+2}-1\right] \Delta g_{n}
\end{aligned}
$$

$$
\delta N_{\mathrm{dwc}}^{L 2}=\frac{R}{4 \pi \gamma} \iint_{\sigma_{o}} S^{L}(\psi)\left[\left.\frac{\partial \Delta g}{\partial r}\right|_{Q}\left(H_{P}-H_{Q}\right)\right] d \sigma_{o}
$$

where $r_{P}=R+H_{P}$ is the spherical radius of the point $P, H_{P}$ is the orthometric height of point $\mathrm{P}, \mathrm{Q}$ represents the moving integration point.

The next two additive corrections are atmospheric and ellipsoidal correction were computed using Eq.7 and Eq.8, respectively. According to Sjöberg (2001), both corrections are reliant on the type of GGM used in modification.

\section{Ellipsoidal correction}

$$
\delta N_{\mathrm{ell}} \approx\left[\left(0.0036-0.0109 \sin ^{2} \varphi\right) \Delta g+0.0050 \tilde{N} \cos ^{2} \varphi\right] Q_{0}^{L}
$$

\section{Combined atmospheric correction (Sjöberg, 1999)}

$$
\delta N_{\text {comb }}^{\mathrm{Atm}}=-\frac{G R \rho^{a}}{\gamma} \iint_{\sigma_{o}} S^{L}(\psi) H p d \sigma_{o}
$$

where $\rho^{\mathrm{a}}$ is the density of the atmosphere at sea level, and equal to $1.23 \mathrm{~kg} / \mathrm{m} 3$ (Sjöberg, 1999).

The total additive correction is illustrated in Figure 8 and it has the following statistics: minimum $=-0.106 \mathrm{~m}$, maximum $=1.013$ $\mathrm{m}$, mean $=-0.0066 \mathrm{~m}$ and standard deviation $=0.0418 \mathrm{~m}$. From the total correction, it is clearly seen that the highest correction was observed on the Titiwangsa Range.

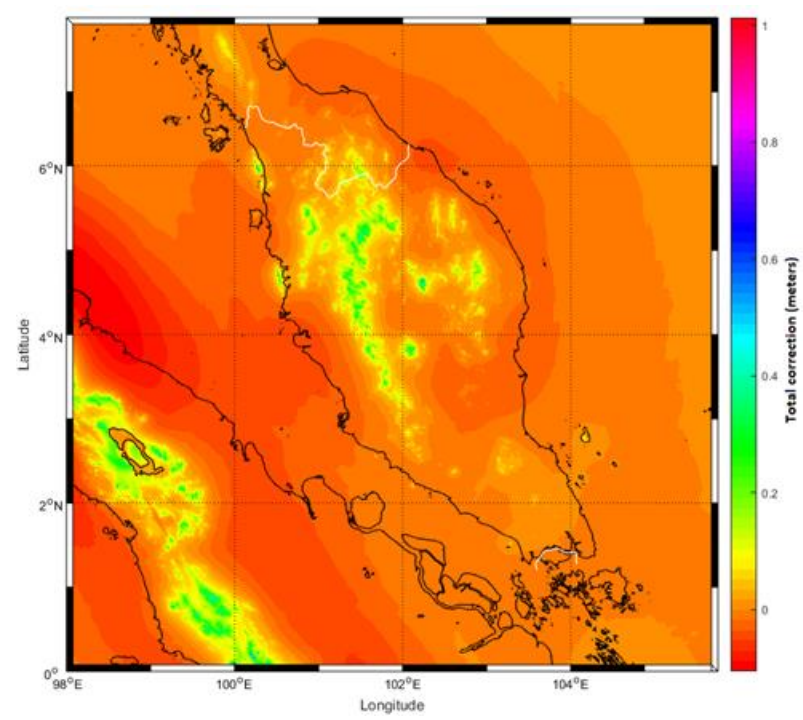

Figure 8 Total additive corrections (Unit: $\mathrm{m}$ )

\section{RESULT}

\subsection{Evaluation the final gravimetric geoid}

The final gravimetric geoid was obtained by adding all the additive corrections to the approximate geoid model as given by Eq.4. Figure 9 (a) and (b) illustrated the final gravimetric geoid computed from the two strategies of gridded free air anomaly 
and the difference between these two geoid models at land region only is shown in Figure 10. From the result, the highest difference between these two geoid models is observed around the Titiwangsa Range, middle part of Peninsular Malaysia. Based on the statistical analysis as shown in Table 3, the minimum, maximum and mean difference are $-0.241 \mathrm{~m}, 0.521 \mathrm{~m}$ and $0.0173 \mathrm{~m}$, respectively. The standard deviation of model 2 (Strategy 2) is slightly smaller compared to model 1 (Strategy 1). In order to evaluate the accuracy of these two models, both models was evaluated using the $173 \mathrm{GNSS} /$ leveling provided by Department of Survey and Mapping Malaysia (DSMM) or JUPEM.

The distribution of the point is shown in Figure 10. For the comparison, the gridded gravimetric geoid was bi-cubically interpolated to the location of GNSS/leveling and the land vertical datum offsets removed using 4 parameter model to fit the gravimetric geoid to local MSL and the standard deviation of residual was then calculated. The current gravimetric geoid for the Peninsular Malaysia was derived using RCR method, WMG03A (Nordin et al., 2005) and KTH method, PMSGM2014 (Sulaiman, 2016) was also evaluated using the same GNSS/leveling. Figure 12 shows the residual between the four gravimetric geoid models and 173 GNSS/leveling, while the RMSE before and after fitting to MSL is shown in Table 4. The discrepancy between gravimetric geoid derived using KTH
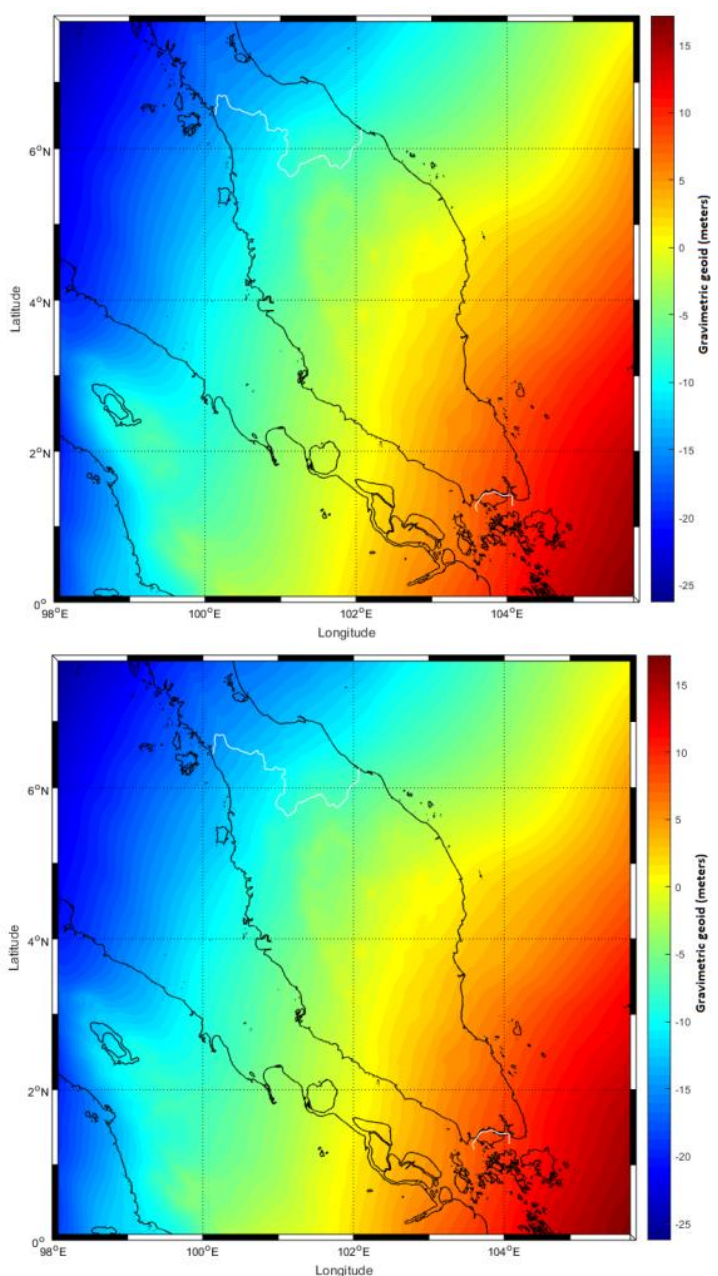

Figure 9 Final gravimetric geoid from (a) Strategy 1, (b) Strategy 2 and (c) difference between the two geoid at land region method (Model 1, Model 2 and PMSGM2014) and GNSS/leveling can be seen to be smaller than derived using RCR method (WMG03A) as shown in Figure 12 where the difference is between $0-0.8 \mathrm{~m}$. Meanwhile, the difference between WMG03A model and GNSS/levelling is about $1-1.5 \mathrm{~m}$.

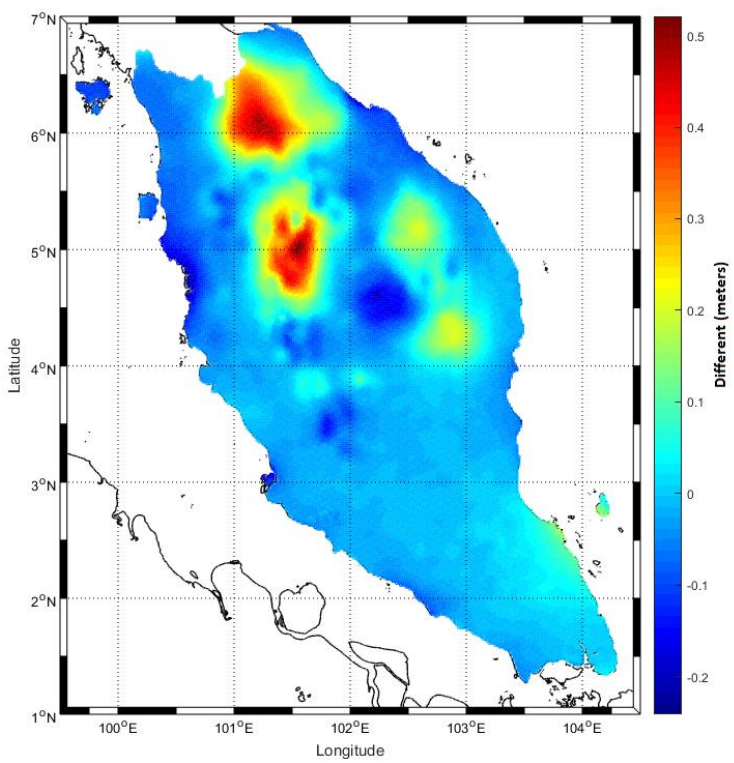

Figure 10 Difference between the two geoid at land region

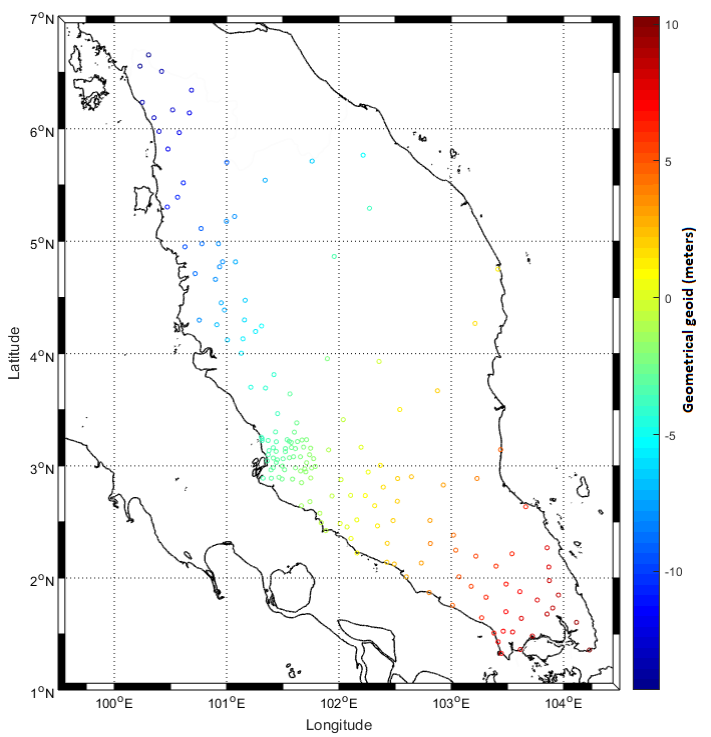

Figure 11 Distribution of GNSS leveling points

Table 3 Statistical analysis of gravimetric geoid (Unit: $\mathrm{m}$ )

\begin{tabular}{ccccc}
\hline & Min & Max & Mean & Std \\
\hline $\begin{array}{c}\text { Gravimetric } \\
\text { geoid - S1 }\end{array}$ & -16.867 & 10.108 & -1.957 & 5.253 \\
$\begin{array}{c}\text { Gravimetric } \\
\text { geoid - S2 }\end{array}$ & -16.762 & 10.095 & -1.961 & 5.249 \\
\hline Different & -0.241 & 0.521 & 0.0173 & 0.1 \\
\hline
\end{tabular}




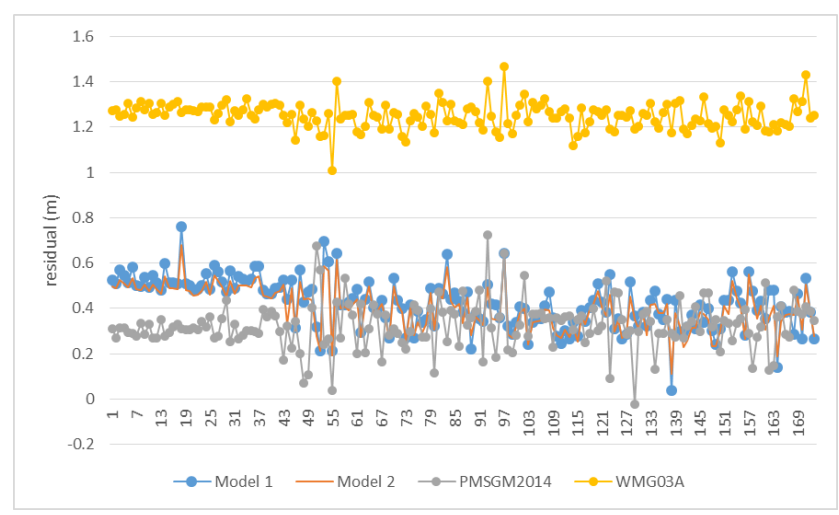

Figure 12 The difference between four gravimetric geoid and 173 GNSS leveling (Unit: m)

Table 4 RMSE before and after fitting to MSL (Unit: $\mathrm{m}$ )

\begin{tabular}{|c|c|c|c|c|}
\hline & $\begin{array}{c}\text { Model } \\
1\end{array}$ & $\begin{array}{c}\text { Model } \\
2 \\
\end{array}$ & PMSGM2014 & $\begin{array}{c}\text { WMG03 } \\
\text { A }\end{array}$ \\
\hline Before & 0.4390 & $\begin{array}{c}0.412 \\
8\end{array}$ & 0.3416 & 1.2519 \\
\hline After & 0.0801 & $\begin{array}{c}0.072 \\
2\end{array}$ & 0.1003 & 0.0519 \\
\hline
\end{tabular}

Based on the result in Table 4, Model 2 is slightly better than Model 1 and has best agreement with the GNSS/leveling with RMSE of $0.4128 \mathrm{~m}$ before and $0.0722 \mathrm{~m}$ after applying the 4 parameter fit. This highlights the advantages of combining terrestrial gravity data using the second strategy before processing using KTH method. Surprisingly, the gravimetric geoid derived in this study, (Model 1 and Model 2) also shows better accuracy than PMSGM2014 after applying the 4parameter fit, although all the geoid models were computed using the same method, which is the is KTH method. It is probably because the terrestrial gravity data used in this study is denser than previous model and also the strategy applied in Model 2. Comparison between Model 2 and WMG03A model shows the WMG03A is better fit to GNSS/levelling as shown in Table 4. However, this was expected since the computation of Model 2 only involved the land gravity and marine data compared to WMG03A, which included the airborne gravity data in the geoid computation. However, the difference of RMSE can be considered small, which approximately $2 \mathrm{~cm}$ less than WMG03A, although using very limited terrestrial gravity data.

\subsection{CONCLUSION}

This study was computed a gravimetric geoid over Peninsular Malaysia using KTH method using limited land gravity data, marine gravity data from DTU17 model and satellite only global gravity model GO_CONS_GCF_2_SPW_R4. In order to combine the land gravity data and marine gravity data which have different accuracy, two strategies of combined and gridding process was applied to produce two different gravimetric models. The first strategy is the common method usually applied by most KTH method users, while the second strategy is usually applied by RCR users to combine different gravity datasets. Therefore, the main objective of this study has been to analyse the effect of these two strategies on the gravimetric geoid accuracy. Evaluation using 172 GNSS/leveling around the Peninsular Malaysia shows strategy
2 is able to improve the accuracy of gravimetric geoid model and surprisingly, the accuracy of both gravimetric geoid derived in this study is better than previous gravimetric geoid derived using KTH method. Comparison with the official gravimetric geoid model for Peninsular Malaysia, WMG03A derived using RCR method, shows the accuracy of gravimetric geoid model derived in this study is not much different (approximately $2 \mathrm{~cm}$ less) but this comparison cannot be seen as an indicator to show that RCR method is better than KTH method because different the data has been used in the geoid computation.

\section{ACKNOWLEDGMENT}

Special thanks to the Department of Survey and Mapping Malaysia (DSMM) for providing terrestrial gravity data and GNSS/leveling data over Peninsular Malaysia. Thanks to the Ministry of Higher Education (MOHE), Malaysia and Universiti Teknologi MARA (UiTM) for their financial funding through FRGS 2018 (Reference code: FRGS/1/2018/WAB08/UITM/03/1). The authors also would like to thank the German Aerospace Center (DLR) for providing TanDEM-X DEM under the project "Towards 1 Centimeters Geoid Model At Southern Region Peninsular Malaysia Using New DEM Model- TanDEM-X” (Proposal ID: DEM_OTHER1156).

\section{REFERENCE}

Abdalla, A., \& Fairhead, D. (2011). A new gravimetric geoid model for Sudan using the KTH method. Journal of African Earth Sciences.

Abdalla, A., \& Tenzer, R. (2011). The evaluation of the New Zealand's geoid model using the KTH method. Geodesy and Cartography, 37(1), 5-14.

Ågren J., (2004). Regional Geoid Determination Methods for the Era of Satellite Gravimetry: Numerical investigations using Synthetic Earth Gravity Models, PhD Thesis, Royal Institute of Technology (KTH), Sweden.

Ågren, J., Sjöberg, L. E., \& Kiamehr, R. (2009). The new gravimetric quasigeoid model KTH08 over Sweden. Journal of Applied Geodesy, 3(3), 143-153.

Amos M.J. (2007) Quasigeoid modelling in New Zealand to unify multiple local vertical datums, $\mathrm{PhD}$ Thesis, Department of Spatial Sciences, Curtin University of Technology, Perth

Andersen, O. B., \& Knudsen, P. (1998). Global marine gravity field from the ERS-1 and Geosat geodetic mission altimetry. Journal of Geophysical Research: Oceans, 103(C4), 8129-8137.

Andersen, O. B., \& Knudsen, P. (2019). The DTU17 Global Marine Gravity Field: First Validation Results.

Ardalan, A. A., \& Grafarend, E. W. (2004). High-resolution regional geoid computation without applying Stoke's formula: A case study of the Iranian geoid. Journal of Geodesy, 78(1-2), $138-156$.

Bae, T. S., Lee, J., Kwon, J. H., \& Hong, C. K. (2012). Update of the precision geoid determination in Korea. Geophysical Prospecting, 60(3), 555-571. 
Bucha, B., \& Janák, J. (2014). A MATLAB-based graphical user interface program for computing functionals of the geopotential up to ultra-high degrees and orders: Efficient computation at irregular surfaces. Computers and Geosciences, 66, 219-227.

Denker, H., \& Roland, M. (2005). Compilation and Evaluation of a Consistent Marine Gravity Data Set Surrounding Europe. In A Window on the Future of Geodesy (pp. 248-253). Springer-Verlag.

Fotopoulos, G., Kotsakis, C., \& Sideris, M. G. (1999). Development and evaluation of a new Canadian geoid model. Bollettino Di Geofisica Teorica Ed Applicata, 40(3-4), 227238.

Forsberg R. (1991) A New High-Resolution Geoid of the Nordic Area. In: Rapp R.H., Sansò F. (eds) Determination of the Geoid. International Association of Geodesy Symposia, vol 106. Springer, New York, NY

Hwang, C., Hsu, H. Y., \& Jang, R. J. (2002). Global mean sea surface and marine gravity anomaly from multi-satellite altimetry: Applications of deflection-geoid and inverse Vening Meinesz formulae. Journal of Geodesy, 76(8), 407-418.

Jamil, H., Kadir, M., Forsberg, R., Olesen, A., Isa, M. N., Rasidi, S.,Aman, S. (2017). Airborne geoid mapping of land and sea areas of East Malaysia. Journal of Geodetic Science, 7(1).

Kiamehr, R. (2006). A strategy for determining the regional geoid by combining limited ground data with satellite-based global geopotential and topographical models: A case study of Iran. Journal of Geodesy, 79(10-11), 602-612.

Kiamehr, R. (2007). Qualification and refinement of the gravity database based on cross-validation approach - A case study of Iran. Acta Geodaetica et Geophysica Hungarica, 42(3), 285295.

McCubbine, J. C., Amos, M. J., Tontini, F. C., Smith, E., Winefied, R., Stagpoole, V., \& Featherstone, W. E. (2018). The New Zealand gravimetric quasigeoid model 2017 that incorporates nationwide airborne gravimetry. Journal of Geodesy, 92(8), 923-937.

Nordin, A. F., Abu, S. H., Hua, C. L., \& Nordin, S. (2005). Malaysia Precise Geoid (MyGEOID). Coordinates, (September), 1-40.

Pa'Suya, M. F., Yusof, N. N. M., Din, A. H. M., Othman, A. H., Som, Z. A. A., Amin, Z. M., Samad, M. A. A. (2018). Gravimetric geoid modeling in the northern region of Peninsular Malaysia (NGM17) using KTH method. In IOP Conference Series: Earth and Environmental Science (Vol. 169). Institute of Physics Publishing.

Piñón, D. A., Zhang, K., Wu, S., \& Cimbaro, S. R. (2018). A new argentinean gravimetric geoid model: GEOIDEAR. In International Association of Geodesy Symposia (Vol. 147, pp. 53-62). Springer Verlag.
Sjöberg, L. E. (2003a). A computational scheme to model the geoid by the modified Stokes formula without gravity reductions. Journal of Geodesy, 77(7-8), 423-432.

Sjöberg, L. E. (2003b). A solution to the downward continuation effect on the geoid determined by Stokes' formula. Journal of Geodesy, 77(1-2), 94-100.

Sjöberg, L. E. (2005). A local least-squares modification of stokes' formula. Studia Geophysica et Geodaetica, 49(1),23-30.

Sjöberg, L. E. (1999) The IAG approach to the atmospheric geoid correction in Stokes' formula and a new strategy. J Geodesy 73:362-366

Sjöberg, L. E., Gidudu, A., \& Ssengendo, R. (2015). The Uganda Gravimetric Geoid Model 2014 Computed by The KTH Method. Journal of Geodetic Science, 5(1). https://doi.org/10.1515/jogs-2015-0007

Sjöberg, L. E. (2007). The topographic bias by analytical continuation in physical geodesy. Journal of Geodesy, 81(5), 345-350. https://doi.org/10.1007/s00190-006-0112-2

Sjöberg, L. E. (2001). Topographic and atmospheric corrections of gravimetric geoid determination with special emphasis on the effects of harmonics of degrees zero and one. Journal of Geodesy, 75(5-6), 283-290.

Sulaiman, S., Talib, K., \& Yusof, O. (2014). Geoid Model Estimation without Additive Correction Using KTH Approach for Peninsular Malaysia. FIG Congress 2014, (June 2014), 1621.

Sulaiman, S.A. (2016) Gravimetric Geoid Model Determination For Peninsular Malaysia Using Least Squares Modification Of Stokes, PhD Thesis, Universiti Teknologi Mara (UiTM), Malaysia

Ses, S., \& Gilliland, J. (2014). Test geoid computations in peninsular malaysia. Survey Review, 35(278), 524-533.

Sandwell, D. T., Müller, R. D., Smith, W. H. F., Garcia, E., \& Francis, R. (2014). New global marine gravity model from CryoSat-2 and Jason-1 reveals buried tectonic structure. Science, 346(6205), 65-67.

Vella, M. N. J. P. (2003). A new precise Co-geoid determined by spherical FFT for the Malaysian peninsula. Earth, Planets and Space, 55(6), 291-299.

Vaníček, P., Najafi, M., Martinec, Z., Harrie, L., \& Sjöberg, L. E. (1995). Higher-degree reference field in the generalized Stokes-Helmert scheme for geoid computation. Journal of Geodesy, 70(3),176-182.

Wessel, B., Huber, M., Wohlfart, C., Marschalk, U., Kosmann, D., \& Roth, A. (2018). Accuracy assessment of the global TanDEM-X Digital Elevation Model with GPS data. ISPRS Journal of Photogrammetry and Remote Sensing, 139, 171-182. 